\title{
DERECHO CONSTITUCIONAL A LA INTIMIDAD Y A LA HONRA
}

\author{
José Luis Cea Egaña \\ Profesor de Derecho Constitucional \\ Pontificia Universidad Católica de Chile
}

Quiero comenzar planteándoles algunas de las razones, con base en las cuales considero que estamos ante un tema de gran importancia para la vida de todos nosotros, y que, por ende, no nos puede resultar ajeno desde ningún punto de vista.

Apartándome un poco de lo que ha sido el esquema que he seguido, deseo leer un breve texto que es parte de una conferencia que pronuncié en la Facultad de Derecho de la Universidad de Chile, el 5 de Agosto de 1996, y que se halla publicada en el № 198 de la Gazeta Jurídica, número correspondiente al mes de Septiembre del año 1996. El pasaje que voy a leer, está extraído de la monografía El Derecho Constitucional a la Intimidad, que es parte, pero sólo parte, de lo que me corresponde exponerles en esta segunda conferencia. Como decía, lo leo con el objeto de que Uds. puedan captar cuál es mi pensamiento en el punto y la razón en atención a la que me parece indispensable defender este derecho.

Creo que la intimidad y la honra, son dos grandes valores o bienes jurídicos a los cuales me corresponde referirme desde el ángulo constitucional. Esos valores se construyen, sobre la base de otro valor jurídico anterior a ellos, y que llamo, siguiendo las palabras que emplea el Tribunal Constitucional de España en una sentencia de 1993, el punto de arranque de todos los derechos humanos. Me refiero al concepto de la dignidad de las personas.

En otras palabras, soy un convencido de que yo tengo derecho a mi intimidad, así como Uds. tienen el suyo, o tengo derecho a mi honra igual que Uds. tienen derecho a la propia, porque somos dignos, o sea acreedores, de una vida íntima y de ser respetados en nuestro honor. Por eso es que el término dignidad es el que necesita una breve clarificación para seguir adelante en esta conferencia.

\section{DIGNIDAD Y DERECHOS}

¿Qué es lo que escribía yo un año atrás y que les voy a repetir en términos más o menos sinóptico?.

Decía lo siguiente: "La dignidad es un valor espiritual y moral inherente a la persona -la dignidad es un valor que solamente tiene la persona humana-. Ella se manifiesta en la autodeterminación consciente y responsable de la propia vida, y que lleva consigo la pretensión al respeto por parte de los demás. La dignidad constituye un mínimo invulnerable que todo estatuto jurídico debe asegurar y que es el "punto de 
arranque" $^{11}$ éstas son las palabras que tomé de la sentencia del Tribunal de España de 1993-, para la existencia, precisión y vigencia de todos los demás derechos humanos".

Entonces, podríamos decir que si ponemos en parangón o en cotejo los derechos humanos con la dignidad personal, concluiremos que este atributo esencial es anterior y más importante que aquellos derechos.

La dignidad, por ende, es la cualidad del ser humano predicable única o exclusivamente como bien atributo de él, coherente con su inteligencia, su igualdad y responsabilidad. Esos atributos de racionalidad erigen a la persona en un depósito máximo o supremo de valores, que integran su espíritu y materia.

El cuerpo también es digno; la mente y el espíritu son por cierto, parte de nuestra dignidad. Es sobre tal base que después son proclamados los derechos y deberes innatos del hombre.

Por eso dije que la dignidad es preeminente a tales derechos, "pues esos derechos humanos son inherentes a la dignidad que tiene la persona. Quebrantar la dignidad es, por ende, lesionar en su esencia los derechos humanos. La dignidad es el más profundo y, por lo mismo, básico de los valores que caracterizan a cada hombre".

Y ahora, en una expresión que me parece completamente de más, habrá que decir que es el más básico de los valores que caracterizan no sólo al hombre sino que a la mujer, a pesar de que el Articulo 25 del Código Civil puntualiza, desde 1857, que siempre que se usa una palabra para referirse a todos los individuos de la especie humana, se entienden abarcados por ella tanto los varones y mujeres sin expresión de edad, sexo, condición o exclusión.

"Esa dignidad es a tal punto constitutiva o configurativa de la personalidad, que sin duda - esto es lo que más interesa hoy en relación con el tema de la información-. ofender la dignidad o destruirla, por ejemplo, a través de la difusión de noticias deshonrosas o la práctica de diligencias policiales o judiciales innecesarias o inconduscentes a los fines legítimamente previstos, por la Constitución y las leyes es desintegrar la identidad propia".

Por eso, veo una relación grande entre la norma constitucional que reconoce el derecho a la "integridad personal", en el Art. 19 № 1 , inciso $1^{2}$, y la dignidad, pues afectar esta última equivale a desintegrar la identidad propia, la integridad de todo ser humano. Afectar tal dignidad es infundir en el sujeto consciente la incertidumbre y la sozobra.

Me imagino, tratando de situarme en el cuadro psicopatológico que vive una persona a la que la han deshonrado y creo que es una situación de incertidumbre, de desconcierto y por cierto, de la mayor amargura. El tratar a una persona no como persona sino como un objeto físico, mutilada su imperecedera calidad de ser humano, quebrantar la dignidad, conlleva angustia, síndromes traumáticos, o la desesperanza más devastadora de la autoestima. Creo que cuando a una persona le destruyen o mancillan la honra o le quebrantan la dignidad pierde ese valor que le permite darle un cierto sentido a su vida, es decir, la autoestima, requerida para emprender, realizar o seguir un proyecto de vida personal. 
Pienso, entonces, que es importante que al iniciar estas explicaciones, no olvidemos la importancia que tiene el concepto de dignidad. Ese concepto, entonces, es el punto de arranque de la intimidad y de la honra.

\section{PANORAMA CONSTITUCIONAL} la honra?

Pues bien ¿qué podemos decir del Estatuto Constitucional de la intimidad y de

Aquí hay una norma, una disposición fundamental que es la que se halla en el Artículo 19 № 4 de la Constitución, la cual es una novedad de la Carta Fundamental vigente.

Dicho sea de paso, ésta es una Constitución que tiene un evidente sentido axiológico, una carga valorativa definida $y_{\text {, en }}$ mi concepto, muy positiva y loable. Las Constituciones anteriores de Chile no se referían a la dignidad y tampoco al derecho constitucional a la intimidad y a la honra. Es una nueva disposición, por lo tanto, sobre un derecho que estaba en la penumbra, implícito sin duda, pero no explicitado en las Constituciones chilenas anteriores.

¿Y qué es lo que la Constitución garantiza en esa norma?.

En dos líneas, vale decir, en una disposición escueta, le plantea al intérprete una cantidad de ideas que son difíciles de aclarar y, lamentablemente, después, en unas doce líneas que continúan, en el Inciso $2^{2}$ de este número 4 , se produce un enredo que resulta ser causa o motivo de conflictos. Como lo mencionaba en la conferencia anterior, esa norma ha suscitado incluso en el Senado de la República, 48 horas atrás, una votación que no deja de ser sorprendente, porque 27 Senadores, o sea el quórum necesario más uno, aprobaron la idea de legislar sobre la libertad de información, pero sin contemplar el delito de difamación, y 11 Senadores, incluido el Presidente de la Comisión de Constitución, Legislación, Justicia y Reglamento, el Senador Miguel Otero, votaron en contra porque consideraban que justamente ese proyecto, tal como se halla en estos momentos, no contempla el delito de difamación que, según ellos, es el que se ha previsto en este Inciso $2^{\circ} \mathrm{N}^{2} 4$ del Artículo $19^{\circ}$ de la Carta Fundamental.

¿Qué es lo que dice el inciso $1^{\circ}$, que es el precepto más rico, en donde propiamente se encuentra la disposición que nos corresponde comentar?

Dice literalmente así : "La Constitución asegura a todas las personas : El respeto y protección a la vida privada y pública y a la honra de la persona y de su familia".

El respeto y protección, naturalmente, no son palabras sinónimas, repetidas sin sentido. Una cosa es respetar, por último sin hacer nada, a través de una conducta de abstención ; y otra cosa es proteger, que denota una idea de conducta activa, de tomar las providencias para que no sea lesionado el valor o bien jurídico de que se trata. Ambas conductas las exige la Constitución, el respeto y protección. Agrega a la vida privada, primero; luego a la vida pública; y por último a la honra de la persona y de su familia. 


\section{PRECISIONES CONCEPTUALES}

Aquí quiero detenerme brevemente a darles una idea de lo que significa cada uno de tales términos.

Vida privada, vida pública y honra de la persona y de su familia.

En materia de vida privada, a diferencia de lo que veíamos en la conferencia anterior en que nadie ha definido lo que es censura previa, aquí nos encontramos exactamente con el fenómeno inverso, pues existe una enorme cantidad de literatura pero solamente unas pocas sentencias, sobre el concepto de vida privada. No podemos aquí, por ende, hacer un examen de esa literatura porque no terminaríamos nunca. La literatura comienza con las publicaciones anglosajonas, cultura en la cual nació el derecho a la intimidad hace ya unos 70 años más o menos. Hay alguna producción chilena en el punto que, podríamos decir, ha ido decantándose para adquirir fisonomía más propia.

En general y en términos simples, digo que la vida privada admite dos niveles de profundidad, en su aproximación a la dignidad que es el factor nuclear o básico de cada yo. Lo que es más cercano al yo se llama la intimidad y dice relación con ciertos datos, conocidos en la legislación extranjera con la expresión "datos sensibles".

\section{¿Qué son los datos sensibles?}

Datos sensibles son aquellos que si se conocen por personas que no sean el titular de ellos, le afectan inevitablemente su autoestima, porque forman parte del santuario de lo más íntimo y de lo más personal de cada sujeto o familia. Creo que no hay ser humano que, incluso frente a su compañero o compañera más cercana y amistosa, no tenga a!go que es absolutamente personal, que es lo más íntimo y de lo cual él solo sabe. Esa zona de los datos sensibles o que dicen relación con la configuración del yo en lo más secreto de la conciencia, o del físico, o de las actitudes, o de los gustos, o de la manera de ser de cada persona. Esos datos o circunstancias forman la esfera de su intimidad. Y podríamos decir casi como en una figura geométrica, que en círculos que son concéntricos pero centrífugos, más allá de la zona de la intimidad o de los datos sensibles de cada ser humano y de su familia, se perfila una zona más periférica o cortical, que podríamos llamar la esfera de la privacidad.

La Privacidad es una expresión que no existe en castellano, pero a fuerza de usarla, incluso el legislador, ha ido adquiriendo carácter de voz utilizable sin caer en error. Privacidad, por tanto es una mala traducción de un anglicismo privacy.

Tendriamos que usar otra expresión, pero como ya se ha ido también dibujando una diferencia entre intimidad, que habría sido el término más correcto, y privacidad, tendríamos ahora que hablar de vida privada, simplemente. La vida privada dice relación con informaciones que no son tan sensibles, pero que siguen siendo hechos o circunstancias que tienen al titular de ella como único y exclusivo interesado en mantenerla bajo reserva, confidencia o secreto. Ya no dicen relación, por ejemplo, con la cuestión sexual, o con la vida conyugal ; tampoco dicen relación con el régimen de almuerzo o cena que tengo yo en la noche con mi señora y mis hijos, ni con el lenguaje que uso con mi hijo menor, ni con mis defectos físicos, a los de mi hija o yerno. Pero si, en cambio, son antecedentes que dicen relación, por ejemplo, con mi cuenta corriente, con mi militancia política, dicen relación con mi patrimonio, con los haberes de mi cónyuge, se refiere a si estoy separado o no de bienes; a las aficciones que tengo, etc. 
Diria que en esta segunda esfera hay muchas informaciones o datos que también tienen a la persona, o a su familia, o a la cónyuge, como los principales y primeros interesados, y que, como regla generalísima, a menos que se demuestre ante la justicia en cada caso lo contrario, no tiene porqué estar publicándose en los diarios, revistas, o televisión como tampoco ser comentadas, porque eso se llama maledicencia o chisme.

Eso equivale a provocar escándalo sin objeto. Es buscar el sensacionalismo por lucro, afán morboso u otra patología social. Y en este sentido son las figuras o personas de preeminencia pública o figuras, los principales que resultan afectados, porque nadie se va a preocupar de un pobre diablo, de cuál es el haber o debe en su cuenta corriente bancaria o por cuánto es deudor de tal o cual cadena de tiendas. Si, en cambio, interesa saber si un Senador por la región tal o cual tiene crédito en el banco o cual es su relación con cierta empresa que vende automóviles o presta servicios remunerados. Hay cuestiones, por lo tanto, que no son tan sensibles, como las primeramente mencionadas que no son íntimas, son más bien corticales y que quedan dentro de lo que se llama la esfera de la privacidad o vida privada, para usar la expresión correcta. Más allá de ese segundo círculo viene la zona de la vida pública. Vida pública que puede ser de carácter social, -mi concurrencia a un cóctel, a una comida, en una recepción, o mi encuentro con otros caminando por las calles de La Serena-; o mi vida política, como persona que vota, que emite una opinión en un diario, o que da un juicio en la cátedra; o mi vida económica, lo que yo pienso sobre el libre mercado, o lo que yo creo que es mejor desde el punto de vista de la libre empresa. Es decir, viene lo que es la vida social, la relación de convivencia, en que coexisto con otros seres humanos y por lo tanto voy dialogando, intercambiando opiniones con ellos coincidiendo o discrepando.

Uds. comprenden que esta tercera zona, la de la vida social, es también importante porque el ser humano naturalmente es un ser social o sociable. Siendo así en este segundo círculo de nuestra vida necesitamos también de un ambiente de confianza y respeto mutuo para desenvolvernos con certeza.

Si hiciéramos un brevísimo momento de detención para reordenar las ideas, partiendo de la base de que éstas son cuestiones complejas, digo que una civilización como la Occidental, como nuestra civilización, como la civilización griego-romana- judeocristiana, de la cual los chilenos, a través de España, somos herederos se caracteriza, sobre todo a partir del pensamiento griego clásico, la filosofía de Aristóteles, de Platón, y recogida en el Derecho Romano, la Edad Media, por la vida privada y su reconocimiento jurídicamente garantizado. Se caracteriza esa cultura por distinguir, de la manera que sea más nítida posible, la esfera de lo público y la esfera de lo privado, y lo trata de diferenciar en términos de que la esfera de lo privado sea la del secreto, la esfera de lo íntimo, de lo confidencial, de lo propio de cada persona o a lo más de su familia, o del núcleo más íntimo de amigos en el caso que una persona hace confidencias con otra. Es ámbito de la confianza íntima en el prójimo, la cual resulta de que no voy a ser delatado y que, por lo tanto, estoy a resguardo. Parto del supuesto que se trata de una zona en que lo íntimo no puede ser objeto de una infidencia o de una deslealtad, de una rúptura del vínculo de confianza recíproca, edificado sobre un profundo sentido y conciencia del respeto. Pero nuestra civilización también reconoce que somos seres sociales y que hay una esfera de lo público. La legislación de Occidente, desde el Derecho Romano, se ha ido estructurando en esta doble esfera, la de lo público y lo privado. Incluso diríamos que forma parte de esa tradición, que es de la cultura occidental, de que a partir de la intimidad que cada cual tiene en su vida privada o en la de 
su familia, se construye la dignidad personal. Nosotros pensamos en la propiedad privada como expresión de privacidad justamente, como prolongación en los bienes de lo que es nuestro yo. Entonces, diríamos que es parte de nuestra identidad tener un casa propia, una familia, gozar de una vida propia, porque se construye la personalidad de cada cual con todas estas circunstancias. A partir de ello yo puedo trazar y realizar en mi vida algo que tenga sentido, que no sea un paso tan dramático como el de quien con angustia exclama : ¡Pero que sentido tiene que yo viva!

Si yo no le encuentro ni descubro sentido a mi vida, si no hallo un horizonte vital que se prolongue en mis hijos, en mi mujer, en mis amigos, en mis alumnos, en algún tipo de relación social o de contribución al bien común, es una amarga existencia la mía, un sobrevivir sin destino ni sentido. ¡Para que vivir!

Creo que la idea de dignidad de la persona, y que se asocia con la intimidad y la construcción de una personalidad propia que le infunde una impronta, una huella a nuestro paso por la tierra, que la hace de alguna manera trascendental o imperecedera, es parte de la aspiración, que no es orgullo sino que dignidad de la persona de cara a los demás. Y eso se proyecta después políticamente, por ejemplo, en algún régimen de gobierno en el cual yo pueda participar con dichas características, y hasta donde yo he pensado en estas materias, creo que reconociendo muchos bemoles y defectos a la democracia, es el régimen político en el cual puedo proyectar más libremente esa esfera de lo íntimo hacia lo público, que es la esfera de la libertad política o de los derechos ciudadanos como el sufragio y la elección periódica de los gobernantes. O sea, creo que hay un sistema que se va imbricando, que es el de las cuestiones personales que terminan proyectándose en las cuestiones políticas, en los asuntos republicanos, en las decisiones públicas.

Con esas ideas en mente paso al segundo concepto, esto es, a la vida pública.

La vida pública no es solamente la vida de las personas que tienen notoriedad ante terceros, como una actriz, un locutor de radio o un entrevistador de televisión. Puede ser un Senador, un Diputado, el Presidente de la República, un Concejal. Pero puede ser también un empresario, un agricultor exitoso, un líder gremial al cual de alguna manera y por ciertos motivos se le reconoce determinado carisma o capacidad para guiar y mandar. Su opinión y comentarios, sus entrevistas, declaraciones son leídas ; sus juicios son escuchados y atendidos, no es ninguna autoridad política o estatal en algunos casos. Pero si lo es en sentido moral o intelectual, artístico o cultural. Esa es una persona de notoriedad pública, aunque no necesariamente es un hombre que ejerza un cargo u oficio público. El Arzobispo de La Serena es una persona de notoriedad pública,aunque no es un hombre que desempeñe una función estatal. Sirve un oficio público, término que es un concepto más amplio que el de índole sólo estatal.

Pues bien, ¿dónde está el principio y en qué punto se halla el fin de la vida pública o de la vida de estas personalidades de notoriedad pública? .

También es un problema responder, porque no se gana mucho con decir que la vida pública termina donde comienza la privada o viceversa, o sea, que la vida privada termina en donde se inicia la vida pública. La pregunta sigue siendo, ¿y en dónde, con objetiva certeza, termina una y comienza la otra?.

Ahi es donde creo que en lugar de ensayar definiciones, de la cuales se han dado muchísimo resulta mejor emplear ciertos criterios operacionales o prácticas aplica- 
bles a la resolución de conflictos concretos. Eso me lleva a pensar en la jurisprudencia y en la actividad de los Tribunales.

La vida pública o la vida de los hombres o personalidades de notoriedad pública, en los términos más o menos amplios que mencioné, es la vida de quienes desempeñan funciones que se encuentran abiertas al público, o que desempeñan roles o ejercen actividades que ellos mismos se encargan de abrir al público. En otras palabras, son personalidades respecto de cuya vida, de cuya conducta, o actuaciones nosotros tenemos derecho a saber, porque ellos mismos se han encargado de abrirles al público su vida. Muchas veces, es cierto, tal la cruz que tienen que llevar no sólo los políticos. Pero aún tratándose de los políticos o de los hombres o mujeres de notoriedad pública ellos también, llega un momento o se topa con asuntos en que, a pesar de abrirse al público, estamos en una zona que es de vida privada. ¿Por qué se defiende la actriz frente a los paparazzi, por ejemplo? ¿Por qué le molesta que la estén filmando en un momento de intimidad?. Porque ella tiene también derecho a una vida íntima, o sea que ella quiere que su notoriedad pública no le impida gozar de su dignidad construyendo un proyecto de vida personal. Con eso se pone de relieve que lo público es suplementario o complementario de lo íntimo: y también se pone así de manifiesto que atacando los elementos de su vida íntima, se le va a causar un daño irreparable a su vida pública.

La vida pública es la vida de los hombres o de las personalidades públicas. Consiste en abrir las fuentes de información sobre ellas a la información y opinión pública, empero, repito que no es una situación absoluta, porque también esas personalidades públicas tienen derecho a la intimidad o al santuario, del secreto de lo personal o de los datos sensibles. Informar sobre esa materia no tiene ningún interés que no sea morboso y, por ende siempre ilegítimo, aunque por lucro u otros designios, se alegue lo contrario.

Queda, por último, el concepto de honra en este esfuerzo por definir tres de las principales expresiones usadas en el Inciso $1^{\varrho}$ del № 4 , de la Norma Fundamental.

Pues bien, la honra es una expresión relativamente más fácil de presentar, porque existe un concepto genérico que es el del honor, el cual obliga a distinguir dos aspectos dentro de esa expresión genérica. Uno es el honor en sentido subjetivo, o sea, mi autoestima, la consideración que toda persona que se aprecie naturalmente siente de sí, aunque por efectos de la destrucción de la autoestima puede quedar abatida y quien sabe que conducta desquiciada llegue a ejecutar. Pero existe otra esfera del honor que es precisamente a la cual se refiere la Constitución y que es la honra, entendiendo por honra la reputación, fama o crédito del cual uno goza ante la sociedad, ante los terceros. Trátase del prestigio, de la buena reputación o fama de hombre de palabra o de una mujer que cumple sus compromisos, que es fiel a su cónyuge, que cumpla con sus obligaciones como madre, profesora, o confidente. De qué prestigio o crédito yo gozo dentro del concierto de mis vecinos, amigos, o de la sociedad en general. La respuesta a esa interrogante se refiere a la honra.

Uno es, por ende, el aspecto que todo ser humano tiene y que es subjetivo, individualísimo, a lo cual he llamado autoestima. Otro es el fruto, o resultado de mi esfuerzo en la vida por construir una imagen y legársela a mis hijos y a mi familia y considero ese legado un tesoro inapreciable que tengo que cuidar y no permitir que sea enlodado. Esa es mi honra u honor en sentido objetivo. 
La Constitución de Chile se refiere a este segundo aspecto, o sea, a la buena reputación, a la merecida fama, al crédito irreprochable del cual una persona goza ante el prójimo en la sociedad.

Y dice que el valor jurídico de la honra también se extiende a la familia. En este sentido, hago hincapié que se dejó constancia en el estudio de la disposición, por la Comisión que la redactó, vale decir la comisión que presidía don Enrique Ortúzar, y por el Consejo de Estado, que la familia queda incluída en el concepto de honra porque, recordando las palabras del antiguo Presidente de la Corte Suprema de Justicia Rafael Fontecilla Riquelme, en un trabajo sobre el tópico publicado en la Revista de Derecho y Jurisprudencia en el año 1960, la honra no termina con la muerte, pues se trata de un imperecedero de los cuales los herederos tienen derecho a disfrutar. Por lo tanto que no se puede mancillar o enlodar la figura de mi padre o de mi abuelo, simplemente denostándolo o por desprestigiarlo.

Aqui hay dos prevenciones que formular.

Algunos autores, sostienen que las legislaciones, o sea, en el Derecho Comparado, el concepto de honra particularmente referido a la familia está en retirada y que la Constitución chilena sería marcadamente conservadora al contemplar el valor de la honra, no solamente referido a la persona sino que a su familia. Respetando tales opiniones, digo que no estoy para nada de acuerdo con tales autores y, en todo caso, no solamente en desacuerdo, sino que tampoco he encontrado legislación alguna en la cual sostener su afirmación. Todo lo contrario, la razón me indica que aun cuando fuere efectivo que en alguna legislación o en alguna Carta Fundamental que no he logrado ubicar, existiera esa situación, no creo que sea para aplaudirla, pues la norma constitucional está bien puesta. Por lo demás en los tratados internacionales sobre derechos fundamentales se insiste en lo que yo aquí defiendo.

Voy a recordar las palabras del fundador de la Epistemología Genética, Jean Piaget, suizo que era jurista y sicólogo, que hizo estudios notables de sicología infantil y escribió un libro que se titula Seis Estudios Sociológicos. En el último de sus capítulos demuestra, de una manera que creo no haber leído nunca con mayor lucidez y brillo, el valor que tiene la idea de respeto, el respetarnos unos a otros para que exista y se consolide una sociedad civilizada. Piaget dice que "el punto en el cual se percibe si una sociedad pasó del salvajismo a la civilización, es la presencia del respeto por el prójimo, por los bienes ajenos, por la honra ajena, por la intimidad ajena, por la autoridad y por las normas. El respeto comienza con cierta cortesía, con determinada educación, con la observancia de reglas que, entre otras, se refieren al Derecho". De manera que Piaget concluye sus estudios de Epistemología Genética explicando cómo la idea del respeto hay que inculcarla desde niño, y cómo la idea de respeto tendría que ser vivida también en la familia, y de ésta, a los difuntos. Ésa es una sociedad civilizada, dice Piaget. Una idea parecida a ésta recoge, varios años después, el filósofo Norberto Bobbio. Ése es, entonces, el objetivo de la norma del Artículo 19 № 4 inciso $1^{\circ}$ de la Constitución.

\section{IV. ¿TENSIÓN ENTRE DERECHOS?}

Comprenderán Uds. que resulta fácil trazar una asociación o ligamen entre ese conjunto de derechos fundamentales -vida privada, vida pública, honra- y la libertad de informar y de opinar. Así lo capta la mayor parte de las personas, pues existe una ten- 
sión, una relación a veces crispante entre una y otra situación, pues los ataques más frecuentes y profundos, los más devastadores e irreparables a la intimidad, a la imagen pública de los hombres públicos y a la honra, se consuman a través del ejercicio ilegítimo de la libertad de informar o del mal llamado derecho a la información.

Esto lo hemos comprobado en Chile y ello ha ocurrido muchísimos años después que en Estados Unidos, Inglaterra y países con sociedades más evolucionadas. En el nombre legítimo de la libertad de informar se ha descendido a afanes sensacionalistas, golpes noticiosos con miras de lucro o figuración, consistentes en enlodar al prójimo, o en destruir la imagen pública de cualquier persona o de una familia, sin reparar el daño causado pretextando que se trata de una libérrima "libertad" de expresión.

Estamos llegando al meollo de mi exposición. Hay, por ende, que detenerse para explicar de qué manera es posible, en definitiva, resolver la dificultad planteada y qué criterios podríamos seguir sobre el particular.

Me he preocupado del asunto, y en la misma versión escrita de la conferencia que ya les mencioné, escribí un capítulo que se llama "Fórmula Operativa". Lo escribí porque, habiendo dado vueltas y nuevas vueltas en torno del problema, seguía sintiéndome poco seguro respecto de cómo conciliar o conjugar el respeto y protección de la honra, la vida privada, y la vida pública, por una parte, con la libertad de informar, por otra. ¿Cómo conciliar la libertad de informar, en la cual yo creo, porque es la libertad madre de la democracia, por una parte, con que se levanten vallas o zonas, diques infranqueables, para que no se pueda informar en la sociedad democrática, de otra?

El problema es grave, pero quiero ser franco en plantearles cuál es la doble dimensión, el doble filo que él tiene.

Pues ya he dicho que el problema, hasta el momento, está o generalmente se visualiza en términos de libertad de informar ilícitamente ejercida para enlodar la intimidad, para destruir la honra o mancillar la vida pública. Entonces la crítica apunta al ejercicio indebido de la libertad de informar. Pero lo que me ha sorprendido constatar es el impresionante crecimiento que tiene lo que se denomina "el derecho a la autodeterminación informativa", como un atributo absoluto, erigido con el designio de impedir que se informe de cuestiones que le interesan evidentemente al público, y que ya no son materias sensibles, ni cuestiones privadas, sino que son escándalos, corrupciones, peculados, delitos puros y simples que se quieren cubrir con el manto de la intimidad para eludir la responsabilidad civil y penal pertinentes. O sea, hemos llegado a una situación en que, dolosamente, se están invocando ciertos derechos que una sociedad tiene que respetar dentro de los límites que los vuelven legítimos, con ficciones jurídicas esgrimidas con un carácter absoluto y que impiden ejercer la libertad de información en cuestiones que le interesan a la opinión pública, en materias que son de la esencia de un gobierno trasparente como lo es el gobierno democrático. Entonces, poco cuesta que yo invoque mi intimidad para que se silencien, por ejemplo, las estafas que pueda haber cometido, o tales o cuales datos concernientes a mi insolvencia.

Siempre recuerdo el caso, por lo demás conocido, pero que me ayuda a ilustrar cómo se puede llegar a abusos con este denominado por la doctrina alemana Derecho a la Autodeterminación Informativa o a la libre disposición de cada sujeto respecto de qué se informa o no de él, en términos absolutos. En Alemania, como digo, ya se llegó a una situación en que culminaron acusándose para aseverar que, de ahora en adelante, 
buscarán una ecuación que permita conciliar la intimidad y la honra, por un lado, con el derecho del público a saber, con la libertad que tienen los medios de comunicación de difundir mensajes, con los bienes jurídicos que son de carácter supraindividual y que se hayan comprometidos. Se quiere silenciar noticias, informaciones, comentarios que son de evidente interés para el público, pero invocando móviles dolosos para esquivar responsabilidades. Se están usando los conceptos de intimidad y honra, se está invocando a veces la imagen pública o privada en términos absolutos, ilimitados, y por ende siempre excesivos, con el objeto de esconder, ocultar o impedir que se ejerza el otro derecho que es el legítimo ejercicio de la libertad de informar. Capten Uds. las consecuencias que esta maquinación dolosa tiene, inevitablemente, para la transparencia de la vida pública y el control que deben ejercer los ciudadanos; y comprendan, igualmente, cómo con el abuso del llamado habeas data, incorporado a las Constituciones Brasilera y Argentina, los deudores pueden sumir en la incertidumbre el desenvolvimiento seguro que se requiere en el comercio.

\section{FÓRMULA OPERATIVA}

El problema es, entonces, difícil porque uno no sabe a ciencia cierta cómo resolver el conflicto. Por eso es que propuse la siguiente fórmula operativa, con la cual deseo ir acercándome al cierre de esta conferencia. Escribí lo siguiente: "La democracia constitucional -en la cual yo fervientemente creo- desde el doble ángulo de lo público y lo privado-de lo cual hemos estado hablando- se tipifica por la información amplia". Yo creo que eso lo comprendemos y compartimos todos. La dictadura se caracteriza, entonces, por la información selectivamente entregada en términos que sean funcionales al jerarca que las proporciona. La democracia es el gobierno abierto, de las cosas públicas en público, como dice Norberto Bobbio. Ésa es la transparencia, característica de la democracia. Se tipifica ella por la información amplia, pero no ilimitada, de mensajes, entre los cuales se cuentan los mensajes sobre asuntos públicos o de relevancia supraindividual.

El pluralismo en las fuentes noticiosas, el libre debate o crítica, la transparencia en las decisiones, la buena fe y confianza en las actuaciones, así como otras cualidades que, incluyendo casos instrumentales de secreto o reserva, convierten a la democracia en el gobierno visible, controlable y responsable por antonomasia.

Claro, Uds. deben comprender que si no somos capaces de, o no nos hallamos habilitados para, fiscalizar y exigir cuentas a nuestros gobernantes, no estamos en democracia. La democracia, en efecto, más que nada exige hoy participación y control. Y para controlar qué requieren Uds.: información. ¡No hay duda! ¿Cómo puedo controlar a una autoridad si no sé lo que hace? Es imposible. Es el concepto que desarrolla Jeremías Bentham en el Panopticon, vale decir, ese Poder que puede mirarnos sin ser visto y controlar sin ser controlado. Ése es el poder que también detenta la información en estos momentos, en que es factible escudriñar la vida ajena sin tener nosotros la menor idea; de que el sujeto a mi lado sabe hasta los últimos detalles de mi vida en materia de datos sensibles. La publicidad, la transparencia, es indispensable para el control y para nuestra propia convivencia democrática. Eso es claro y que quede más claro aún.

En esa democracia, en la cual creo, rige un principio que conjuga dos bienes jurídicos, los armoniza o integra coherentemente. Son dos bienes jurídicos antagónicos 
sólo en apariencia, porque creo que una buena jurisprudencia, una rica actividad de interpretación jurídica tiene que resolver sin sacrificar un principio al otro, ya que todos los derechos fundamentales están llamados a ser disfrutados. Ése principio de conjugación de la libertad de informar, con el respecto de la vida privada y de la vida íntima, de la honra de la persona y de la familia y de la vida pública o de los hombres de notoriedad pública, exige integrar las siguientes cinco reglas. Esto es lo que yo llamo la "fórmula operativa".

Tal vez, resulte un tanto técnico y tedioso exponerlas, pero ojalá tenga la claridad y logre transmitir la importancia que encierra captar estas cinco reglas. Las voy a ir leyendo una tras otra, en la secuencia que reputo lógica, que permite a un juez, a un abogado o a un ciudadano defender una causa, en la que, aparentemente, estén en conflicto dos bienes jurídicos inalienables y esenciales.

Esta fórmula operativa tiene como primera regla la siguiente: "Tratándose de la vida pública, en una democracia siempre tiene que prevalecer la libertad de información".

La vida de un Senador o Diputado, como parlamentarios; de un Intendente, o Gobernador como tales, no tiene por qué ser ocultada a los ciudadanos. Ése es el fenómeno que dos grandes profesores de la Universidad de Concepción, Ramón Domínguez Benavente y su hijo Ramón Domínguez Águila llaman, en un frase hermosa, "las servidumbres a que obliga la grandeza". Si yo quiero ser Senador y servir con rectitud mi oficio, tengo exponerme a muchas críticas y no esperar sólo aplausos y sonrisas. Tengo que abrir mi vida a todos quienes son mis conciudadanos, mis electores o las personas que de alguna manera pueden o no darme su apoyo. Sería absurdo que, siendo parlamentario, me mantuviera al margen de ellos, aislado o escondido del escrutinio público. Lo más probable sería, en tal caso, que no fuera reelegido o sea calificado como un mal político y un deplorable Senador. Y lo que digo de él lo predico de cualquier persona de notoriedad pública.

Tratándose de la vida pública, repito, prevalece la libertad de información. Subrayo la libertad de información en los término ya definidos y no el derecho a ella, o sea, la facultad de exigir que se entregue la información que yo decida.

Veamos la regla segunda: si se trata de la vida privada o de la vida íntima -ahí viene la discusión si acaso nos quedamos solamente con el nivel de privado o calamos más hondo para penetrar en lo íntimo- es preeminente el derecho a la intimidad y, naturalmente, también el derecho a la honra.

Ésta es la zona de lo que he llamado los datos sensibles. Aquellos que, realmente, me interesan a mí, a mi cónyuge, a mis hijos; le interesan a mi familia, pero no al vecino ni, probablemente, siquiera a mi más íntimo amigo. Ésa es la zona, digamos, que desde la Grecia clásica constituye el área de configuración y realización de mi vida y que yo la quiero mantener como un santuario secreto e infranqueable, inviolable, desde el cual pueda proyectar mi existencia para llevarla a la sociedad. Ésa tiene que ser una zona de intimidad y de respeto irrestricto.

Paso a la tercera regla: "La libertad de información, el derecho a la intimidad, el derecho a la vida privada, a la vida pública y a la honra, tienen, todos, excepciones que los vuelven derechos de ejercicio legítimo". Yo he dicho mil veces que no existen derechos absolutos. Creo que hay un solo derecho absoluto, pues ni siquiera la vida es un 
derecho sin límites. Me refiero al derecho a no ser nunca torturado, psicológica ni físicamente. Pero salvo ese caso excepcionalísimo, los derechos de los cuales estamos hablando tienen siempre excepciones.

¿Y cuáles son esas excepciones? Son salvedades, ya que el secreto de lo íntimo o de la privacidad, no puede invocarse para encubrir el dolo propio, o lesionar el bien común, o dejar en riesgo la seguridad del Estado o la seguridad nacional. Tampoco la publicidad de la información -en este caso entra en juego la libertad de informar-puede esgrimirse con el fin de afectar lo que ese mismo bien común exige cautelar para beneficio de todos, que es el de la intimidad. O sea las excepciones tienen que ser de derecho estricto.

Las excepciones para penetrar en el santuario de lo íntimo tienen que ser cuidadosamente configuradas por el legislador para precaver que, con el pretexto de ellas, se haga tabla rasa de la que debe ser la regla general ya explicada. $Y$ lo mismo digo en sentido contrario, o sea, que las excepciones a lo público, en que para informar yo tengo que penetrar en los asuntos públicos porque está comprometido el interés público, tienen que estar claramente establecidas ya sea por la jurisprudencia, o bien por la legislación, con el objeto de no invertir esa misma regla general.

Llego así a la cuarta regla: "Lo privado del hombre público existe siempre".

Ya lo he dicho, lo privado de las personas o personalidades de notoriedad pública jamás desaparece, porque ellos siguen siendo seres humanos. Aquí no me resisto a recordar un caso relativamente reciente, el del difunto Presidente de Francia François Mitterrand. Uds. saben que él sufrió una penosa y larga agonía, pero manteniendo plena lucidez. En medio de grandes dolores por el cáncer de próstata que padecía, el médico de cabecera recogió y registró sus confesiones en el lecho de muerte. $Y$ después de fallecer, las publicó en un libro.

$Y$ entonces se invocó en defensa tanto la libertad de informar como la proscripción de la censura. Y se publicó un libro. La viuda de Mitterrand, que es un personaje importante en Francia, sabedora de que se encontraba a punto de entrar en circulación la obra, dedujo un recurso frente a un tribunal de París, pidiendo que el libro fuera requisado, argumentando la violación del secreto profesional y, peor todavía, la lesión a la intimidad y a la imagen pública de su marido y el recuerdo de su vida como estadista. Sobre todo, pidió que el Tribunal ordenara la requisición del libro por quebrantar el valor de la intimidad, de la imagen pública que tiene el Presidente de Francia difunto y su vida pública y, por último, a raíz de incurrirse en el delito de quebrantamiento de secreto profesional. Uds. saben, por otra parte, que en un caso no exactamente semejante, salvo que este segundo ejemplo se refiere también a un libro, en Chile a mediados de mayo de 1993, la Corte de Apelaciones y un mes después la Corte Suprema, ordenaron la incautación del libro Impunidad Diplomática del periodista Martorell. Hasta el día de-hoy, sin embargo, estamos disputando en la Comisión y en la Corte Interamericana de Derechos Humanos de la O.E.A., o sea no es una causa juzgada, no es una materia irrevocablemente resuelta por los Tribunales de Justicia.

Vean Uds. la rapidez con que se resolvió el problema por la justicia francesa y ahí nadie alegó que había censura previa y tesis por el estilo. Y si alegaron censura previa, la Corte la desestimó, porque hay valores jurídicos que son preeminentes y que no se pueden lesionar. Por eso, lo privado del hombre público existe siempre, incluso 
después de muerto, pero con magnitud más reducida que la de un ciudadano común, porque ya les dije se halla aquí la situación de un hombre al cual se le impone el concepto de la servidumbre a que obliga la grandeza.

$Y$, finalmente, no es suficiente alegar una finalidad de protección de valores íntimos o de intereses públicos para esquivar el imperativo de informar sobre cuestiones de interés supraindividual. Por eso comencé esta conferencia diciendo que todo el mundo se preocupa de los abusos que cometen los medios de comunicación social en perjuicio de la intimidad, de la honra personal o familiar. Pero, ¿por qué no se ponen a pensar en los abusos que están cometiendo los particulares invocando dichos bienes jurídicos 0 , incluso las autoridades públicas, para que no se diga una palabra de ellos cuando es legítimo hacerlo?

Aquí, no sea que se olvide, es donde yo quiero insertar el problema de la difamación. Sé que Uds. van a tener, en este Ciclo, el honor de escuchar la siempre interesante y lúcida exposición de mi distinguido amigo, el Senador Miguel Otero. Si mal no recuerdo el programa lo contempla como autoridad que cierra las conferencias y se va a referir exactamente al asunto de la difamación. Yo debo decir -y ojalá que no incurra en una actitud que pudiere ser calificada de poco leal con un amigo ausente- que soy profundamente contrario a que se contemple en Chile la figura de la difamación.

\section{CRÍTICA A LA DIFAMACIÓN}

Lo he sostenido por todos los medios legítimos que he tenido a mi haber en contra de la regulación del Artículo 19 № 4 inciso segundo de la Constitución, ese que llamaba de las diez líneas confusas y rebuscadas.

En mi concepto son letras sin espíritu noble, profundamente negativas y extremadamente peligrosas. Soy contrario a la difamación y me opongo a que en el proyecto que se está discutiendo en el Congreso, el inciso Segundo del Artículo 19 № 4 de la Carta Fundamental sea regulado en términos que a mi parecen son sumamente peligrosos.

Soy contrario a contemplar la difamación, en primer lugar, porque es un concepto que, salvo la Ley Francesa de 1884, no está tipificado en ninguna legislación positiva de Estados democráticos modernos. Se han buscado otros caminos para hacer justicia preventiva o ex post, a propósito de la protección de la intimidad, de la honra o de la vida pública, pero sin recurrir a la difamación.

Salvo esa Ley Francesa de 1884 -y Uds. comprenderán que 113 años significa mucho en la vida del Derecho-, en este momento ningún sistema jurídico contempla la difamación por ser ambigua, confusa, equívoca y, a raíz de eso y más, muy peligrosa para la comunicación social libre y segura en la sociedad democrática.

Alguien me podría decir: Bueno, el hecho que tenga 114 años esa Ley no es un argumento de fondo para invalidar su copia en Chile.

Respondo diciendo que la Ley Francesa ha sido desfigurada por los tribunales del mismo país, porque ante el disparate de la ley han optado desde la Corte de Casación para abajo, por hacer una interpretación pro bono, la cual, simplemente, se ha traducido que no se aplica tal Ley. Es una especie de resto náufrago de cara a los cinco requisi- 
tos copulativos exigidos por los tribunales franceses para que sea aplicable. En la práctica es una ley que no tiene ya vigencia.

Y salvo el caso francés no existe ninguna legislación en el mundo democrático que en este momento contemple la difamación.

¿De donde viene -una tercera razón que me parece que va acercándonos al fondo- el rechazo mayor que yo tengo a esta disposición? Soy un convencido que legislar o dictar disposiciones constitucionales sobre la base de traumas personales es un error gravísimo.

Imponer normas jurídicas sobre la base de lo que me pasó, pensando que le va a suceder a los demás, no es una manera serena, prudente, equilibrada, sensata y balanceada de dictar preceptos de trascendencia. Lamentablemente la difamación, en los términos con que se quiere contemplarla en el Artículo 19 № 4 inciso segundo de la Constitución, es una disposición que tiene nombre y apellidos que, por respeto a las personas que redactaron esa norma, prefiero callarlos aquí.

Pero esa norma tiene origen histórico concreto, el diario "Clarín", y los ataques injustos, alevosos, inaceptables, en contra de ciertas personalidades públicas, lo cual no autoriza para que se dicte una norma constitucional que puede tener efectos muy negativos en un proceso seguro, sereno y confiado y de libertad de información. Así como reconozco que la libertad de información tiene límites, yo estoy por una libertad de información segura dentro de esos límites, pero no crearle, además, figuras que son indefinibles como la de la difamación, utilizables para amordazar a los medios de comunicación por quienes no toleran que se diga nada, aunque sea notorio, que los afecte.

Y ahí está el último punto. La figura punible de la difamación, en efecto, nadie la ha podido definir, nadie ha podido decir hasta el momento en qué consiste como un tipo penal distinto de la injuria o de la calumnia, una y otra en sus diversas especies. Tanto es así que los penalistas que han estudiado más a fondo los delitos contra el honor o contra la vida pública o privada hablan de una injuria difamatoria, con lo cual la confusión se torna completa. Es decir, no sé si es injuria, o es difamación, o se mezclan las dos figuras punibles.

La figura penal de la injuria, tipificada en el artículo 416 del Código Penal, es muy vasta: Toda expresión proferida o acción ejecutada en deshonra, descrédito o menosprecio de otra persona.

¿Dónde está el problema, entonces? Él yace no solamente en que es incierta la diferencia entre la difamación y la injuria. El problema está, más hondamente, en que es típicamente chileno exigir un dolo especial para configurar la injuria o para tipificar la calumnia, esto es, el animus injurandi o la intención dolosa específica, de segundo grado. Entonces es al examinar ese dolo específico que los tribunales chilenos han ido creando esta figura del doble dolo, por virtud del cual rechazan generalmente las querellas por injurias e, incluso, las deducidas por calumnias.

Pero esto, como se comprende, es una cuestión de jurisprudencia.

¿Cómo voy a obligar a los Tribunales a que cambien su criterio hermenéutico? ¿Qué es lo que va a ocurrir en la Magistratura si se aprueba la difamación? Creo que los tribunales van a buscar por uno u otro camino salir adelante sin condenar: frente a la 
presión, social y de los medios, de que la libertad de información está amagada, una salida, una coartada por último, por la cual no lleven a la cárcel a los periodistas será la del dolo doble, como he dicho.

Entonces vamos a terminar en lo mismo, en un clima malo que es el del enrarecimiento derivado de una disposición peligrosa, ambigua, susceptible de entendimiento discrecional y que, en definitiva, por eso y más, no debe ser regulada, porque creo que es más el perjuicio que el beneficio que cabe esperar de la legislación sobre ella.

Por último, en el afán de superar todas estas objeciones se ha dicho que si bien la difamación no sea tipificada - pues no se puede tipificar, con claridad, como delito penal-, se quiere recoger una palabra ambigua, una expresión polisémica que se usa, repitiendo la palabra el artículo 10 № 3 de la Constitución de 1925 . Me refiero a la palabra "abuso".

¿Recuerdan Uds. que en la primera conferencia de esta tarde les dije que el sistema legal chileno es de responsabilidad ex post, porque se responde por los delitos o abusos cometidos después de haber ejercido la libertad de informar?

Pues bien, hoy en el Senado hay un grupo de Parlamentarios que dicen: "Ahí está la solución". La palabra abusos permite imponer responsabilidades civiles, el pago de indemnizaciones fuertes, en el carácter de perjuicios morales que afectan a la intimidad, al honor, a la vida privada o, quién sabe, a la vida pública. No hay que ser un experto en materia de indemnizaciones de perjuicios por daño moral, para llegar a la conclusión que es de sumo peligro que haya tanta elasticidad normativa en materia de comunicación social. Se comienza hablando de millones de dólares o de cientos de millones de pesos, que en el caso de ser condenados los modestos medios de comunicación social -estoy pensando especialmente en los regionales- puede significar lisa y llanamente su bancarrota o cierre. Entonces digo: ¿hasta dónde rige, con la difamación, una ecuación que concilie la libertad de informar con que sobre mi vida no se puede decir una palabra, aunque le interese al prójimo por estar comprometido el interés real de informar a la sociedad sobre asuntos que la afectan o pueden perjudicarla?

\section{CONCLUSIÓN}

Por eso es que termino diciendo que no es cuestión de alegar que está de por medio mi intimidad, la vida privada. He sido resueltamente partidario de defender esos valores, pero también no me puedo callar que también soy un fervoroso partidario de la defensa de la libertad de expresión.

Las cinco reglas que he resumido deben conjugarse para acertar con un resultado concreto. No basta simplemente invocar la quinta regla, la intimidad mancillada, no basta esgrimir la honra para saltar la crítica pública que muchas veces es necesaria. Lo que se exige es que estos problemas sean, en definitiva, resueltos caso a caso por los Tribunales. Creo que ésa es la lección más importante que yo podría dejar acá.

No creo que en estas materias tan complejas y dinámicas, que van cambiando día a día, pueda siquiera suponerse que los casos son iguales. Por el contrario, queda de relieve la necesidad de ir con la jurisprudencia, caso a caso, aplicando la equidad, pa- 
Revista de Derecho - Universidad Católica del Norte - Sede Coquimbo - 1998

rámetros o criterios, matrices, principios generales trazados en la Constitución y las leyes.

Me parece que el legislador tendría que optar por criterios certeros, claros, de modo que después los tribunales, interpretándolos de manera favorable a los derechos fundamentales, en este caso, la intimidad y la honra, hagan lugar a otro derecho humano fundamental que es la libertad de expresión, sin quebrantarlo en su esencia. 